\title{
Combined ventricular output and oxygen delivery are reduced while oxygen extraction fraction is increased in fetuses with Ebstein's Anomaly by MRI
}

\author{
Meng Yuan Zhu ${ }^{2,1^{*}}$, Ioana A Stochitoiu', Edgar Jaeggi', Shi-Joon Yoo', Lars Grosse-Wortmann', \\ Christopher Macgowan ${ }^{3}$, Mike Seed ${ }^{1,2}$
}

From 19th Annual SCMR Scientific Sessions

Los Angeles, CA, USA. 27-30 January 2016

\section{Background}

Ebstein's anomaly (EA) has variable prognosis. New MRI technology allowing the measurement of vessel blood flow and oxygen content could provide additional prognostic information in the setting of fetal EA.

\section{Methods}

We measured fetal weight, brain weight and lung volume in normal and EA fetuses using MRI. Blood flow and T2 in the major fetal vessels were measured using our previously published technique. Fetal oxygen delivery (DO2), consumption (VO2) and extraction fraction (OEF) were calculated using estimated fetal hemoglobin concentration.

\section{Results}

We studied 30 normal and 8 EA fetuses at 36 weeks gestation. There were 2 deaths in the 4 patients that underwent surgery (all Starnes procedures). We found reduced flows in all measured vessels except ascending aorta (Table 1). There were also significant reduced T2s in ascending aorta and superior vena cava, but no difference in umbilical vein (UV) and descending aorta (Table 1). DO2 was lower, but increases in OEF maintained normal VO2 in EA fetuses (Table 2). Fetal weight and brain weight were lower in EA fetuses, while lung volume was not significantly different (Table 2 ). Within the EA group, UV flow $(\mathrm{P}=0.04), \mathrm{VO} 2(\mathrm{P}<0.0001)$ and lung volume $(\mathrm{P}=0.03)$ were significantly higher in EA newborns not requiring surgery than EA newborn that received surgery.

\section{Conclusions}

MRI revealed a $\sim 50 \%$ reduction in CVO in EA fetuses compared to normal fetuses, which is greater than any other type of CHD. While EA subjects had similar placental function (indicated by similar UV T2), lower $\mathrm{CVO}$ resulted in reduced UV flow, therefore decreased DO2. EA fetuses had increased OEF compensating for the reduced DO2, but body and brain development were still reduced. In addition, MRI-based lung volume

Table 1 MRI measured flow and T2 in major fetal vessels in normal and Ebstein's anomaly fetuses.

\begin{tabular}{cccccc}
\hline & CVO & UV & AAo & SVC & DAo \\
\hline Normal mean flow (ml/min/kg) & $451 \pm 56$ & $129 \pm 29$ & $205 \pm 47$ & $132 \pm 31$ & $248 \pm 45$ \\
Ebstein's mean flow (ml/min/kg) & $233 \pm 45$ & $83 \pm 17$ & $219 \pm 40$ & $93 \pm 32$ & $135 \pm 33$ \\
P value & $<0.0001^{*}$ & $<0.0001^{*}$ & 0.4 & $0.01^{*}$ & $<0.0001^{*}$ \\
Normal mean T2 (ms) & & $192 \pm 34$ & $119 \pm 23$ & $84 \pm 13$ & $99 \pm 17$ \\
Ebstein's mean T2 (ms) & & $196 \pm 26$ & $90 \pm 15$ & $74 \pm 8$ & $84 \pm 22$ \\
P value & & 0.8 & $0.0005^{*}$ & $0.01^{*}$ & 0.3 \\
\hline
\end{tabular}

CVO: combined ventricular output; UV: umbilical vein; AAo: ascending aorta; SVC: superior vena cava; DAo: descending aorta. - * indicates significantly different result.

${ }^{2}$ Institute of Medical Science, university of Toronto, Toronto, ON, Canada

Full list of author information is available at the end of the article 
Table 2 Oxygen consumption, oxygen delivery and oxygen extraction fraction, fetal weight $Z$ score, fetal brain weight $Z$ score and lung volume in normal and Ebstein's anomaly fetuses.

\begin{tabular}{lcccccc}
\hline & VO2 $(\mathbf{m l} / \mathbf{m i n} / \mathbf{k g})$ & $\mathbf{D O 2}(\mathbf{m l} / \mathbf{m i n} / \mathbf{k g})$ & OEF & Fetal weight $\mathbf{Z}$ score & Brain weight Z score & Lung volume \\
\hline Normal & $7.0 \pm 1.9$ & $20.1 \pm 5.1$ & $0.35 \pm 0.07$ & $0.2 \pm 0.6$ & $0.1 \pm 0.9$ & $64 \pm 24$ \\
Ebstein & $6.3 \pm 1.3$ & $13.4 \pm 2.5$ & $0.47 \pm 0.09$ & $-0.3 \pm 0.5$ & $-1.3 \pm 0.7$ & $55 \pm 17$ \\
P value & 0.3 & $0.008^{*}$ & $0.01^{*}$ & $0.03^{*}$ & $0.0003^{*}$ & 0.3 \\
\hline
\end{tabular}

VO2: oxygen consumption; DO2: oxygen delivery; OEF: oxygen extraction fraction. - * indicates significantly different result.

measurements, UV flow and VO2 maybe associated with postnatal outcome in EA fetuses. Therefore, with more experience, the MRI technique may provide useful prognostic information in Ebstein's anomaly pregnancies.

\section{Authors' details}

${ }^{1}$ Cardiology, The Hospital for Sick Children, Toronto, ON, Canada. ${ }^{2}$ Institute of Medical Science, university of Toronto, Toronto, ON, Canada. ${ }^{3}$ Physiology \&

Experimental Medicine, Hospital for Sick Children, Toronto, ON, Canada.

Published: 27 January 2016

\section{doi:10.1186/1532-429X-18-S1-071}

Cite this article as: Zhu et al:: Combined ventricular output and oxygen

delivery are reduced while oxygen extraction fraction is increased in

fetuses with Ebstein's Anomaly by MRI. Journal of Cardiovascular Magnetic

Resonance 2016 18(Suppl 1):071.
Submit your next manuscript to BioMed Central and take full advantage of:

- Convenient online submission

- Thorough peer review

- No space constraints or color figure charges

- Immediate publication on acceptance

- Inclusion in PubMed, CAS, Scopus and Google Scholar

- Research which is freely available for redistribution

Submit your manuscript at www.biomedcentral.com/submit 